\title{
Igualdad de género: un enfoque alternativo desde el lenguaje filial del cuerpo
}

\author{
Gender Equality: An Alternative Approach from \\ the Viewpoint of the Filial Language of the Body
}

\author{
José GRANADOS \\ Pontificia Università Lateranense. Istituto Giovanni Paolo II \\ Roma. Italia \\ ID ORCID 0000-0002-8935-984X \\ granados@istitutogp2.it
}

Resumen: El artículo examina cómo las teorías de «igualdad de género» han pasado, de basarse en la libertad, a apoyarse en el ser. Aborda primero la obra de Martha C. Nussbaum que, partiendo de las capacidades humanas básicas, intenta una fundamentación universal de los derechos homosexuales. Se fija después en Judith Butler, quien juzga necesario desmontar la estructura de heterosexualidad hegemónica opresora de libertades. Finalmente se propone una alternativa desde la experiencia del cuerpo relacional, como cuerpo generado o filial. El papel estructurante de la diferencia hombre-mujer, al permitir que el camino de la persona hacia su origen se despliegue más allá de quienes la generaron, aparece como necesaria para defender la igual dignidad de todos.

Palabras clave: Género, Cuerpo, Diferencia sexual, Ideología, Creación, Derechos LGBTI, Iglesia Católica, Martha C. Nussbaum, Judith Butler, Benedict XVI.
Abstract: The article examines how «sender equality» theories have shifted from being based on freedom to being based on being itself. It first addresses the work of Martha C. Nussbaum who, starting from the basic human capabilities approach, attempts a universal foundation for homosexual rights. It then turns to Judith Butler, who deems it necessary to dismantle the structure of hegemonic heterosexuality that oppresses freedom. Finally, the article proposes an alternative that draws from the relational experience of the body, considered as a generated (or filial) body. The structuring role of the sexual difference, by allowing our path towards our origin to unfold beyond those who generated us, appears as necessary to defend the equal dignity of all.

Keywords: Gender, Body, Sexual Difference, Ideology, Creation, LGBTI Rights, Catholic Church, Martha C. Nussbaum, Judith Butler, Benedict XVI. 


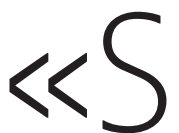

i hasta ahora habíamos visto como causa de la crisis de la familia un malentendido de la esencia de la libertad humana, ahora se ve claro que aquí está en juego la visión del ser mismo, de lo que significa realmente ser hombres» ${ }^{1}$. Esto decía Benedicto XVI en un discurso a la curia romana a finales de 2012, describiendo la visión contemporánea del género. Al mencionar el paso de la libertad al ser, el Papa detectaba una evolución en el pensamiento actual sobre sexo y género. Pues algunos enfoques propios de la modernidad, para justificar nuevos comportamientos y derechos sexuales, han aceptado el sexo como algo dado, y han postulado una libertad ajena a él. Mientras que ahora madura otra visión que no acepta que haya algo dado en el sexo, el cual pasaría a ser obra de la misma libertad humana.

En realidad podríamos decir que ambas visiones siguen subsistiendo, y sirven para apoyar, de diversos modos, la postura que, bajo el lema de «igualdad de género», busca eliminar la diferencia hombre-mujer como pilar constitutivo de la vida humana y de la sociedad. La respuesta a la pretensión de tal «igualdad de género» tiene que hacer frente, por tanto, a dos desafíos. El primero procede a partir de una idea autónoma de la libertad, que considera que el cuerpo sexuado es externo o ajeno a esta libertad, la cual se constituye y obra al margen del cuerpo sexuado. El segundo, por el contrario, acepta la importancia del cuerpo para la libertad humana, y por eso pretende redefinirlo, hasta eliminar cualquier orden previo de dicho cuerpo.

Para describir estas dos corrientes, me centraré en los escritos de dos conocidas filósofas: Martha Nussbaum y Judith Butler. Una vez expuesto su pensamiento, propondré una respuesta a estas dos corrientes, postulando que el cuerpo personal está dotado de un lenguaje propio, al cual pertenece la diferencia hombre-mujer, y que este lenguaje es parte necesaria de todo ejercicio genuino de la libertad.

\section{La visión liberal de Martha C. Nussbaum}

Un primer modo de argumentar a favor de la llamada «igualdad de género» y de la redefinición del matrimonio para que incluya a personas homosexuales, capaces incluso de adoptar hijos, sigue la visión liberal clásica de la razón ilustrada. Como representante notable de este punto de vista se halla

${ }^{1}$ Cfr. Benedicto XVI, «Discurso a la curia romana» (21 de diciembre de 2012), AAS 105 (2013) $47-54,50$. 
la profesora norteamericana Martha Nussbaum. Nussbaum, que asume muchos rasgos del pensamiento de Aristóteles, trata los temas de feminismo y de justicia sexual en la línea del liberalismo kantiano, y de su continuación en John Rawls².

\section{Una ética universal basada en las capacidades humanas}

Es clave para este punto de vista la afirmación de la dignidad singular de la persona, dotada de derechos que han de ser reconocidos por todos. Para justificar esta visión universal, que no depende de tal o cual contexto social (y que permite juzgar todo contexto), Nussbaum considera adecuada la perspectiva de Rawls, que identifica bienes y recursos básicos debidos a toda persona. A su vez, Nussbaum corrige a Rawls en cuanto ella pasa, de centrarse en los bienes básicos, a centrarse en lo que cada individuo puede hacer con esos bienes, enfoque que denomina «the capabilities approach». Esta mirada se inspira en Aristóteles, quien describía la vida buena desde las actividades centrales del ser humano, cuyas excelencias son las virtudes ${ }^{3}$.

Desde aquí elabora nuestra filósofa una lista de aquellas capacidades humanas que deberían garantizarse a toda persona para que esta florezca. En la lista aparecen: poder vivir una vida suficientemente larga y sana, poder moverse libremente y con seguridad, poder satisfacer la propia sexualidad y reproducirse, poder usar los sentidos, el pensamiento, las emociones..., poder asociarse a otros... ${ }^{4}$

Nussbaum entiende que esta lista de capacidades básicas está abierta a discusión, y reconoce también que nuestros prejuicios culturales distorsionan el modo en que comprendemos tales capacidades. En este punto reconoce el valor de los trabajos de Michel Foucault, donde el autor francés explica aspectos centrales de nuestra visión del mundo a partir de ciertas estructuras so-

\footnotetext{
${ }^{2}$ Me centro sobre todo en los escritos donde Nussbaum expone su visión sobre derechos homosexuales: Nussbaum, M. C., Sex \& social justice, Oxford: Oxford University Press, 1999. Con respecto al liberalismo de Nussbaum en cuestiones feministas, cfr. AввEY, R., The Return of Feminist Liberalism, Montreal: McGill-Queen's University Press, 2011, parte III: «The feminist liberalism of Martha Nussbaum».

3 Cfr. Nussbaum, M. C., «Non-Relative Virtues: An Aristotelian Approach», Midwest Studies In Philosophy 13 (1988) 32-53; ID., «Nature, Function, and Capability: Aristotle on Political Distribution», Oxford Studies in Ancient Philosophy, Supplementary Volume 1 (1988) 145-184; ID., «Human Functioning and Social Justice: In Defense of Aristotelian Essentialism», Political Theory 20 (1992) 202-246.

${ }^{4}$ Para una lista detallada, cfr. Nussbaum, M. C., Sex \& social justice, op. cit., 41.
} 
ciales que generan esta visión, estructuras que se convierten así en instrumentos de poder sobre nosotros.

La construcción social de nuestras categorías tiene, por tanto, mucho peso, pues nos obliga a revisar algunos presupuestos acríticos, pero Nussbaum no ve en esto, como sí lo veía Foucault, razones para el desánimo, sino al contrario: saber de este peso social significa saber también de la posibilidad de cambio, porque lo social es transformable, aunque lo sea con fatiga ${ }^{5}$. Por eso mantiene que podemos llegar a descubrir un punto de vista ético universal, que no cambie según los contextos, y que no dependa solo de las preferencias individuales, las cuales pueden estar distorsionadas, como ocurriría en el caso de esclavos que amaran su esclavitud.

Ahora bien, a este punto de vista universal no se llega aislándose de todo contexto, sino desde dentro mismo del contexto humano y del diálogo ético entre los hombres. El universalismo de Nussbaum quiere evitar todo presupuesto «metafísico» y basarse solo sobre la experiencia común compartida. Así, no tiene valor ético, por ejemplo, acudir a la naturaleza o a otro factor objetivo externo a nuestra experiencia racional y a la conversación entre nosotros. Nussbaum defiende, por eso, que, aun cuando la ética debe tener en cuenta la biología, ya que esta constituye un factor relativamente estable en la vida de los hombres, ningún argumento ético puede decidirse «porque un biólogo haya descubierto algo» ${ }^{6}$.

\section{Ética de las capacidades y derechos bomosexuales}

En este contexto se sitúa el discurso de Nussbaum sobre los «derechos» homosexuales, los cuales derivan del concepto liberal de la dignidad del individuo, entendida desde la defensa de las capacidades humanas. Pues respetar a la persona es respetar que pueda ejercitar su sexualidad, y esto sucederá, para algunos, según las inclinaciones homosexuales que les son propias, porque firmemente radicadas en el ser de ellos.

\footnotetext{
5 Al respecto, cfr. Nussbaum, M. C., «Constructing Love, Desire, and Care», en Nussbaum, M. C. y Estlund, D. M. (eds.), Sex, Preference, and Family: Essays on Law and Nature, Oxford: Oxford University Press, 1997, 253-276.

${ }^{6}$ Nussbaum, M. C., «Aristotle on Human Nature and the Foundations of Ethics», en Altham, J. E. J. y Harrison, R. (eds.), World, Mind, and Ethics: Essays on the Ethical Philosophy of Bernard Williams, Cambridge: Cambridge University Press, 1995, 86-131, 123; ID., Sex \& social justice, op. cit., 40.
} 
Pero, ¿no han defendido todas las culturas anteriores a la nuestra que la diferencia sexual entre hombre y mujer es el único modo de ejercer la sexualidad que puede ser reconocido socialmente? Concluir esto no tiene fundamento, según Nussbaum, quien aporta como prueba su estudio de la cultura griega antigua ${ }^{7}$. Pues, sigue diciendo, esta cultura no juzgaba el valor moral de un acto sexual según que el compañero de tal acto perteneciera al mismo o a distinto género. Nussbaum deduce de aquí que la cultura griega, aun siendo muy diferente de la contemporánea, puede ayudarnos a superar nuestros prejuicios sobre la sexualidad.

En concreto, puede ayudarnos a superar el prejuicio de incluir en la lista de capacidades humanas universales que deben ser garantizadas la de poder contraer solo un matrimonio diferenciado sexualmente. Nussbaum da importancia, sí, al cuerpo, precisamente porque ofrece una base universal común (pensemos, por ejemplo, en que tenemos similares necesidades nutritivas), pero entre las propiedades universales del cuerpo no incluye la diferencia sexual entre hombre y mujer.

Desde aquí argumenta Nussbaum la necesidad de permitir el matrimonio a personas del mismo sexo. Un elemento clave de su discurso consiste en desligar el matrimonio de la procreación. La sexualidad, según Nussbaum, es un bien en sí, sin que haya que buscarle otros fines extrínsecos a ella. Nussbaum arguye que, de hecho, se permite el matrimonio a personas estériles, las cuales no pueden procrear. Por la misma razón se debería permitir, por tanto, a personas del mismo sexo. Como se ve, aquí la sexualidad se considera solo en cuanto afecta a cada individuo, y no en cuanto da forma a un tipo de relación entre los individuos, en cuyo caso podría tener sentido proteger la misma relación hombre-mujer, independientemente de que sea fértil o no. Más adelante volveré sobre este punto.

Aun desligando matrimonio y procreación, Nussbaum aboga también por la concesión del derecho a la adopción de hijos para personas del mismo $\operatorname{sexo}^{8}$. Interesa el modo en que la filósofa americana argumenta que las parejas homosexuales puedan adoptar hijos. Tal cosa se deduce, primeramente, porque hay que garantizar las capacidades humanas que definen una vida bue-

7 Nussbaum, M. C., «Platonic Love and Colorado Law», en ID., Sex \& social justice, Oxford: Oxford University Press, 1999, 299-331.

${ }^{8}$ Nussbaum, M. C., «A Defense of Lesbian and Gay Rights», en ID., Sex \& social justice, Oxford: Oxford University Press, 1999, 184-210. 


\section{JOSÉ GRANADOS}

na, y entre ellas está que sea posible tener descendencia. El punto de vista es, por tanto, el de los adultos, y no tanto el de los hijos, de los cuales se considera solo que necesitan el cuidado de los adultos en general. Como veremos, no se tiene en cuenta aquí que el hijo no solo es cuidado por los padres, sino que procede corporalmente de la diferencia sexual de ellos, y que esta procedencia corporal queda grabada en la identidad misma del hijo. Se olvida así una dimensión importante del cuerpo, en cuanto que este recuerda el papel constitutivo de la filiación para nuestra identidad. Desde este punto de vista no es ni mucho menos indiferente para el hijo que se garantice en cuanto sea posible la presencia de un padre y una madre $\mathrm{o}$, al menos, cuando estos faltan, una referencia a la diferencia sexual de la que él procede. Es un punto sobre el que volveremos andando nuestro discurso.

Puede concluirse que en la visión de Nussbaum lo que define a la persona es su libertad y capacidad de actuación, ante todo como individuo y no como parte de un grupo orgánico donde las relaciones son constitutivas de cada persona. Desde esta visión se razona que la diferencia hombre-mujer no es una coordenada común de lo humano. Las capacidades necesarias para una vida buena, aun cuando tienen en cuenta el cuerpo en general y también el ejercicio libre de la sexualidad, no dan relevancia a la condición sexuada de hombre o mujer. Como señalaré más adelante, mientras Nussbaum subraya justamente las capacidades básicas de la persona, olvida que existe también una receptividad básica, la cual es igualmente decisiva para la vida buena y que depende, como veremos, del reconocimiento del propio origen en su padre y madre.

Antes de responder a algunos aspectos centrales de la propuesta de Nussbaum, paso a describir una mirada alternativa en apoyo del género, con presupuestos harto diferentes.

\section{JUdiTh ButLER Y LA LUCHA CONTRA LA HETEROSEXUALIDAD HEGEMÓNICA}

Butler parte de un presupuesto distinto de Nussbaum, más inspirado en la crítica que los llamados maestros de la sospecha (Marx, Nietzsche, Freud) dirigen al pensamiento iluminista ${ }^{9}$. En efecto, estos sospechan que, tras los argumentos de la supuesta razón universal, hay otras fuerzas ocultas que consti-

\footnotetext{
9 Cfr. Ricoeur, P., De l'interpretation. Essai sur Freud, Paris: Seuil, 2014 [1965], cap. 2, apdo. 3.
} 
tuyen las verdaderas «razones». Y Butler, por su parte, se pone a la zaga de autores, como Michel Foucault, que llevan al máximo esta sospecha ${ }^{10}$. Como veremos, mientras Nussbaum considera el cuerpo sexuado (es decir, marcado por la diferencia sexual) como terreno neutro, y ve la condición sexuada como dato biológico a tener en cuenta para el juicio ético, aunque no sea nunca determinante; Butler ve el mismo cuerpo sexuado como estructura opresora de la libertad y a la que hay que hacer frente, desmontándola ${ }^{11}$. Aquí se puede intuir ese paso de la libertad al ser de que hablaba Benedicto XVI.

\section{La identidad corporal, herramienta de opresión social sobre la persona}

Es interesante observar que Butler rechaza una oposición radical entre natura y cultura y, por tanto, entre sexo y género. Butler se opone a la idea de que existe, por una parte, un sexo dado y, por otra, un género establecido culturalmente, que podría no tener nada que ver con ese sexo. Esto sería, según Butler, un dualismo inaceptable, que traduciría la oposición cartesiana cuerpo-mente. Aún más, hay que rechazar este dualismo porque refleja una oposición hombremujer, donde al hombre se le asocia la cultura, a la mujer la naturaleza.

A este rechazo, por dualista, de la oposición sexo-género, se asocia el rechazo de la posición existencialista sartriana. Para Butler la postura de Sartre, según la cual la persona podría modelar radicalmente su género, se basa en un individualismo que, subrayando la autonomía, no tiene en cuenta los lazos de interdependencia que vinculan a los hombres entre sí ${ }^{12}$. El género no está simplemente a disposición de la persona, porque esta no es libre ante la presión del discurso social, sino más bien tiende a ser fuertemente determinada por este discurso.

Esto significa que Butler mira al «yo» como integrado en un tejido de relaciones sociales que, de alguna forma, habita al «yo» por dentro, constituyéndolo en su intimidad. Por eso la acción libre está siempre condicionada por el contexto, y este suele ser un contexto de poder que se impone sobre los in-

${ }^{10}$ Me limito al estudio de las obras más influyentes de la autora para la cuestión de género: BUTLER, J., Gender trouble: Feminism and the subversion of identity, New York-London: Routledge, 2011 (1990); ID., Bodies That Matter: On the Discursive Limits of Sex, New York-London: Routledge, 1993; ID., Undoing gender, New York-London: Psychology Press, 2004.

${ }^{11}$ Es el tema principal de BUTLER, J., Bodies That Matter, op. cit.

12 Cfr. Butler, J., «Beside Oneself: On the Limits of Sexual Autonomy», en ID., Undoing Gender, op. cit., cap. 1. 
dividuos. De hecho, Butler piensa que este contexto puede cambiarse solo lentamente y solo con mucha dificultad, por lo que propone la parodia como estrategia de resistencia, parodia que pone en ridículo al sistema y, de este modo, lo debilita.

Es claro el influjo de Michel Foucault sobre la feminista americana. Para Foucault, nuestra corporalidad nos sujeta al poder controlador de la sociedad. Foucault ha estudiado el tema con respecto al sistema carcelario (control sobre la persona a través del cuerpo preso) o a los hospitales (control de las personas a través de la salud). La sexualidad es otro modo en que, según Foucault, este poder se ejerce sobre el ser humano. Eso sí, mientras Foucault tiende a pensar que estas normas implícitas terminan imponiéndose, Butler cree que es posible plantarles cara poco a poco a través de acciones comunes.

Este emplazamiento del individuo en un tejido social que le oprime en su misma identidad de persona, plantea una oposición entre el discurso cultural (que se presenta insidiosamente como «natural») y el deseo corporal de cada uno. Tal oposición entre discurso cultural y deseo individual sustituye en Butler al par cultura - natura. El discurso cultural (el cual incluye la palabra y el lenguaje, pero también rituales, costumbres, prácticas...) es una forma inevitable en que se ejerce el poder sobre las personas, de modo acaso anónimo e involuntario, constituyendo una suerte de «inconsciente social» ${ }^{13}$. Tal discurso determina socialmente el deseo, de modo que algunos deseos resultan imposibles, mientras que otros se dan por supuestos. ¿Y cuál es el discurso social dominante?

\section{La matriz heterosexual hegemónica}

Butler piensa que el discurso dominante básico es el discurso de hegemonía heterosexual, que tiende a medirlo todo en términos binarios «hombremujer», como si esta diferencia fuese un referente ineludible, y no creación de ese mismo discurso ${ }^{14}$. Vivimos así en una sociedad determinada por una matriz heterosexual hegemónica, que se impone tiránicamente sobre el deseo y las formas de amar. Y todo con el agravante de que este discurso sobre el sexo no está solo formado de palabras y acciones, sino que queda inscrito en el cuerpo

\footnotetext{
${ }^{13}$ Sobre el concepto, cfr. Hopper, E., The Social Unconscious, Philadelphia: J. Kingsley, 2003; WeINBERG, H., «So What is this Social Unconscious Anyway?», Group Analysis 40 (2007) 307-322.

${ }^{14}$ Cfr. Butler, J., Gender Trouble, op. cit., 41-42.
} 
de la persona, haciéndose así mucho más incisivo y oprimente ${ }^{15}$. La visión marxista sobre la ideología, como superestructura teórica que oculta los verdaderos intereses inconfesables, se aplica ahora al cuerpo mismo, que lleva tatuada una ideología radical.

Así las cosas, la propuesta de Butler sobre el género apuesta por erosionar la ideología dominante heterosexual, entendiendo que el género no está medido desde tal hegemonía heterosexual fija, sino que tiene un carácter performativo ${ }^{16}$. Esto quiere decir que el género no se constituye previamente a nuestra acción, sino en ella, según actuamos o representamos un papel social. Y tal constitución del género sucede, no por una acción aislada, sino por la repetición continua de acciones. Además, no se trata de una acción individual autónoma y sin límites, sino de una acción condicionada socialmente y con fronteras claras, que consiente solo un rango transformativo modesto.

De ahí que la lucha contra esta injusticia no pueda llevarla a cabo el individuo aislado y su libertad, pues lo que se requiere es transformar el tejido social donde el individuo se ha instalado. El esfuerzo contra la hegemonía heterosexual se mueve contra una opresión que se ha inscrito, por siglos, en la corporalidad del hombre. Dada la fuerza de la matriz heterosexual compulsiva, gran parte de la acción tomará, come indiqué más arriba, la forma de una parodia, que se burla de las formas existentes y, de este modo, las pone en ridículo y las deslegitima ${ }^{17}$. Este punto es uno de los que ha merecido a Butler la crítica feroz de parte de Nussbaum, quien acusa a Butler de derrotismo, así como de olvidar los elementos universales de la condición humana. Estos elementos universales son justamente, reprocha Nussbaum a Butler, los más necesarios en la lucha por el bien de las mujeres, cuyos problemas básicos se dan en países no occidentales y se refieren a la falta de capacidades humanas básicas: sufren hambre y violencia, una educación pobre, falta de acceso al trabajo y de igualdad ante la ley... ${ }^{18}$

Ahora bien, notemos que, en el enfoque de Butler, el objetivo no es solo permitir más capacidades (aumentar derechos), entre las cuales lo heterosexual

${ }^{15}$ Cfr. Butler, J., Bodies That Matter, op. cit., 15-16.

${ }^{16}$ Cfr. ID, Gender Trouble, op. cit., 183-193.

${ }^{17}$ Cfr. ibid., 107-193.

${ }^{18}$ Nussbaum, M. C., «The Professor of Parody: the Hip Defeatism of Judith Butler», New Republic 220 (1999) 37-45; sobre las diferencias y semejanzas de Butler y Nussbaum, cfr. MACKENZIE, J., «Refiguring Universalism: Martha Nussbaum and Judith Butler - An Uneasy Alliance?», Australian Feminist Studies 24 (2009) 343-358. 
sería una capacidad (o derecho) más, sino que se quiere transformar el campo social, determinando de otra forma la vida de todos. Se reconoce, así, que la relación hombre-mujer también habrá de cambiar, dada la relación inextricable entre la sociedad entera. Por eso hay una violencia implícita en esta visión, violencia que se justifica porque se consideran a su vez violentas las formas heterosexuales hegemónicas.

Con estos presupuestos deduce Butler que el género no es algo separado dualísticamente del cuerpo, sino un estilo o forma de tener un cuerpo. Este estilo, además, está situado socialmente, lo que limita sus capacidades expresivas, pero, en todo caso, es capaz de desafiar al imperialismo dominante de la diferencia heterosexual, a través de las acciones performativas que tal imperialismo dominante no puede evitar que se realicen. Ante este deseo de desmontar el discurso cultural opresor queda en pie, sin embargo, una pregunta ineludible.

\section{¿Hay un sexo anterior al discurso cultural?}

Butler llega a afirmar que, incluso aquello que llamamos sexo, no es un dato natural previo, pues considerar natural al sexo es ya un resultado de la ideología heterosexual. Por eso puede defender nuestra autora que el mismo sexo esté mediado culturalmente ${ }^{19}$. Es decir, también la determinación pretendidamente «biológica» de lo que es ser «hombre» $\mathrm{o}$ «mujer» tiene ya un lenguaje o sentido al que no puede accederse desde fuera del discurso cultural.

En todo caso, Butler no parece negar que haya algo previo en el cuerpo sexuado mismo, limitándose a afirmar que esto previo nunca se da fuera de la acción humana que lo constituye, la cual se halla situada en un discurso cultural. La pregunta ineludible es, pues, cómo valorar ese «algo previo» que está en el cuerpo, esa alteridad radical de la carne de que hablaba Paul Ricoeur, alteridad que nos precede, pues estaba ya ahí antes de que la eligiéramos ${ }^{20}$. Y tal precedencia, nótese, es a la vez temporal y fundante, ya que la carne no solo es la memoria más antigua, sino que la carne contiene en cada momento, y desde dentro de nuestra acción misma, la vigencia e influjo de esa memoria primera.

Es claro que esto previo no consiste para Butler, en ningún caso, en el dimorfismo sexual del cuerpo. ¿De qué se trata, entonces? Si eso previo fuera

\footnotetext{
${ }^{19}$ Es la tesis que Butler intenta sostener en BUTLER, J., Bodies that matter on the discursive limits of «sex», New York: Routledge, 2011.

${ }^{20}$ Cfr. Ricoeur, P., Soi-même comme un autre, Paris: Seuil, 1990, 369-380.
} 
solo materia inerte, ordenada a partir de un proceso evolutivo determinista o azaroso, entonces no se podría asumir el cuerpo dentro de la propia persona, porque esta materia resultaría extraña a un proyecto personal. El hombre estaría unido a una materia que en último término introduciría un «no-sentido» en la comprensión de sí y de su camino. La tecnología podría modificar ese residuo (proyecto cyborg), pero solo hasta un cierto punto. Además, el dualismo entre yo y cuerpo se prolongaría en un dualismo interpersonal, pues el cuerpo es ámbito irrenunciable de contacto con los otros.

Con todo, creo que Butler reconoce con más claridad que Nussbaum, sea la importancia que tienen el cuerpo y el sexo para emplazar socialmente a la persona, sea la interdependencia radical de cada individuo, a través del mismo cuerpo y sexo. Esto le lleva a desconfiar de toda visión universal que acomune a los hombres, temiendo que bajo ella se escondan nuevas formas de opresión. Nussbaum, por su parte, aparece como paladín de la libertad del individuo, y también de la razón comunicativa entre los hombres, los cuales son capaces de ponerse de acuerdo sobre datos universales de la vida buena, superando los prejuicios culturales, por fuertes que puedan ser. Pero en este enfoque el cuerpo sexuado tiende a jugar solo un papel externo a la persona libre y racional.

Estas reflexiones nos ayudan a vislumbrar en el cuerpo, como frontera entre la persona y su mundo, y como enlace entre lo recibido y lo obrado por ella, el lugar donde explorar alternativas que, aceptando la apertura relacional de la persona, como pide Butler, permitan una visión compartida de lo humano, según las exigencias racionales de Nussbaum. Todo esto pasará por replantear la importancia de la diferencia hombre-mujer.

\section{UNA VISIÓN ALTERNATIVA DESDE EL «LENGUAJE DEL CUERPO»}

El reconocimiento de la diferencia hombre-mujer como estructura de la vida personal y social ha sido compartida por todas las culturas anteriores a la nuestra. Nussbaum alude a la excepción de la visión griega, pero lo que prueba como mucho es que aceptaban la homosexualidad, pero no la relación homosexual en paralelo con el matrimonio como base para la vida en sociedad, con capacidad incluso de adoptar y educar hijos ${ }^{21}$. La pregunta es si esta

${ }^{21}$ Cfr. Brown, P., The body and society: men, women and sexual renunciation in early Christianity, New York: Columbia University Press, 1988, 5-32. 
asunción cultural generalizada es, como quiere Butler, el efecto de una opresión, no solo patriarcal, sino de heterosexualidad hegemónica. Vamos a ver, al contrario, que la referencia a la diferencia sexual resulta elemento irrenunciable de la identidad personal, así como riqueza que la sociedad debe proteger.

\section{El cuerpo como alteridad originaria de la persona en el mundo}

Parto de la condición encarnada de la persona humana, que la sitúa en el mundo y entre los otros. El cuerpo es, ante todo, la pasividad o receptividad originaria, la apertura primera de nuestro ser a la presencia del mundo y de los otros. Esto no significa que el cuerpo sea algo ya dado de forma inmutable, que solo haya de aceptarse sin más. Sabemos, al contrario, que el cuerpo, especialmente en su entramado afectivo y sexual, se presenta al hombre como tarea, y tiene por eso rasgos performativos, es decir, que se configuran cuando el hombre actúa. Solo que esa tarea no se desarrolla en el vacío, sino que se apoya sobre un dato previo irreducible, que estamos llamados a integrar como componente de nuestra acción, pues la precede y la posibilita.

Pues bien, uno puede considerar este dato previo como un elemento ajeno a toda razón y sentido humano. O lo puede ver, al contrario, como dotado de un lenguaje que no hemos inventado nosotros. Lo que no puede hacerse es ignorar este dato ni reducirlo totalmente al resultado del querer propio o a la sedimentación a lo largo de los tiempos de un querer común. Los intentos de Butler por hacer del sexo algo producido por el discurso cultural chocan con un obstáculo último que no puede ser rebasado.

¿Cómo entender eso previo, que es inseparable de nuestra condición encarnada? La pregunta es crucial, como antes dijimos, pues, si eso previo fuera ajeno a toda lógica humana (si se debiera a la necesidad ciega o al azar), sería imposible integrarlo en la propia humanidad, y quedaríamos condenados a un dualismo que nos dividiría por dentro y, además (dado que el cuerpo es lugar de encuentro interpersonal), nos dividiría también del mundo común de los otros. Voy a intentar mostrar en lo que sigue que solo si eso previo contiene la diferencia sexual de hombre y mujer es posible, por un lado, la aceptación total del propio cuerpo, escapando al dualismo. Además, solo si eso previo contiene la diferencia sexual es posible una relación de respeto mutuo entre personas consideradas iguales y libres en la sociedad. 


\section{La referencia de la persona a su origen, y la diferencia sexual}

El límite que señala el cuerpo, límite irreducible al propio plan o proyecto, nos indica un hecho esencial de la condición humana: el hecho de que hemos nacido, hemos sido engendrados por otros. Esto significa que la alteridad irreducible del cuerpo va unida al vínculo con quienes nos han traído al mundo. Aquello que, en el cuerpo, no está bajo nuestra elección ni control, aquello que es receptivo y dependiente, nos refiere a este vínculo con los que nos han generado.

Se abre así una vía para que la receptividad primera del cuerpo pueda alcanzar sentido y, de esta forma, ser integrada plenamente en nuestra identidad, hasta decir con paz: «yo soy mi cuerpo» ${ }^{22}$. En efecto, tal apropiación del propio cuerpo (y, con él, de la propia finitud y de todo lo concreto que somos sin haberlo elegido) pasa por la apropiación del vínculo con quienes nos han precedido, en primer lugar con nuestros progenitores. Si esa relación con ellos se acepta como buena, tendremos un apoyo para aceptar como buena la propia corporalidad. Por eso la relación con ellos es también clave en el proceso educativo.

Pues bien, precisamente aquí, en la recepción primera del cuerpo propio al nacer, se halla el punto originario donde la diferencia sexual incide en la vida de toda persona, la cual no puede ser generada sin intervención de lo masculinofemenino. La pregunta por la diferencia pertenece por tanto a la pregunta «quién soy yo», en cuanto esta pregunta se liga a aquellos que me han dado origen.

En vista de los desarrollos de la técnica, que permite la fecundación in vitro, ¿qué valor puede tener que la persona proceda de una diferencia sexual? Ocurre que el hecho de haber sido engendrados por otras personas, de que cada generación venga al mundo desde la anterior, puede convertirse en una dominación excesiva de unas personas sobre otras. Esto podría suceder, sea por comportamientos inadecuados de las personas concretas, sea también, y este es un punto decisivo, por la estructura o ambiente mismo en que estas personas concretas traen al mundo a la generación siguiente. ¿Qué ocurre cuando una persona es traída al mundo dejando al margen, en la medida en que es posible (nunca lo es del todo), la diferencia hombre-mujer?

El problema ha sido puesto de relieve, desde dentro de la tradición liberal, por Marcel Gauchet en su escrito El bijo del deseo ${ }^{23}$. Gauchet subraya que

\footnotetext{
${ }^{22}$ MARCEL, G., «L'être incarné, repère central de la réflexion métaphysique», en ID., Du refus à l'invocation, Paris: Gallimard, 1940, 19-54, 30; Merleau-Ponty, M., Phénoménologie de la perception, Paris: Gallimard, 1945, 175.

23 Gauchet, M., «L'enfant du désir», Le Débat 132 (2004) 98-121.
} 
en las sociedades occidentales modernas todo hijo resulta ser hijo deseado por sus padres, y que su existencia de hijo se explica desde este deseo de ellos, sin que intervenga ahora, como sí lo hacía antaño, el factor anónimo de la naturaleza. Resulta, entonces, que ser «hijo del deseo» trae consigo consecuencias negativas en la educación y maduración de la persona, pues el hijo tenderá a concebir toda su existencia como resultado del deseo de sus padres, un deseo que determinará entonces el horizonte de las acciones del hijo y será clave para decidir del éxito o fracaso de la vida de él.

¿Qué relieve cobra, ante esta cuestión, la referencia del cuerpo del hijo a la diferencia sexual de los padres?

a) Esta diferencia asegura, por una parte, la vinculación del hijo con los padres. Es decir, gracias a la diferencia, de donde el hijo proviene, existe una relación con los padres que permite al hijo aclarar la relación con su propio cuerpo. La aceptación integral del propio cuerpo queda ligada, entonces, a la aceptación de la diferencia hombre-mujer.

b) A la vez, la misma diferencia asegura también que el hijo no se refiere solo a los padres, pues estos no tienen en su mano la diferencia sexual, que desborda a cada uno de ellos. Es decir, ese vínculo con los padres no termina directamente en las personas que le han engendrado, sino que se abre más allá de ellas, garantizando que el hijo pueda presentarse en plano de igualdad, y no medido solo por los deseos de los padres. Así que la diferencia asegura un trasfondo común compartido por padre y madre, un trasfondo que no está controlado por ellos y, así, respeta la libertad del hijo.

Este argumento se sitúa en la línea del que aporta Habermas cuando critica la modificación genética para producir una raza humana mejor dotada (con aumento de memoria, por ejemplo, o de coeficiente intelectual). Habermas arguye que, aun cuando parezca que se está mejorando la generación siguiente, existe el peligro de diseñar una generación según la imagen ideal de la generación presente, que se proyectaría en la futura ${ }^{24}$. Pues bien, la negación de la diferencia sexual como trasfondo generativo y educativo de la persona actúa en el mismo sentido, aun cuando no modifique los genes, ya que modifica las condiciones de nacimiento y educación de los hijos, midiéndolas según los deseos de los padres.

${ }^{24}$ Cfr. Habermas, J., Die Zukunft der menschlichen Natur: Auf dem Weg zu einer liberalen Eugenik?, Frankfurt: Suhrkamp, 2001; KAMPOWsKi, S. y MolTisanTI, D. (eds.), Migliorare l'uomo? La sfida etica dell'enhancement, Siena: Cantagalli, 2011. 
Desde este punto de vista, la diferencia sexual surge como el ambiente o terreno apto para que el hijo responda a la cuestión de sus orígenes. La defensa del matrimonio es la defensa de un tal ambiente, necesario para la sociedad en cuanto es el único idóneo para la educación de sujetos libres. Por eso puede entenderse que la sociedad permita el matrimonio entre un hombre y una mujer estériles, aunque no puedan tener hijos, en cuanto que está afirmando y protegiendo el tipo de ambiente adecuado para que una persona venga al mundo y constituya su identidad personal.

De ahí, también, que todo matrimonio, al unir a un hombre y una mujer, sea el lugar idóneo para la adopción, en cuanto que, manteniendo el ambiente propio de la generación, mantiene el ambiente propio de la educación. En efecto, la adopción tiene que hacer lo posible para que el hijo, a quien le faltan aquellos que le han generado, no pierda la referencia al lugar donde fue generado, es decir, a la relación entre un hombre y una mujer. De este modo se mantiene su origen abierto más allá de su padre y de su madre, ya sean biológicos o adoptivos.

Hay, pues, en la constitución de la persona humana un trasfondo o ambiente originario de relaciones, radicado en el cuerpo, y que no es obra del hombre, pues cada persona lo encuentra ya ahí al nacer, para arraigarse y crecer en él, de modo parecido a como encuentra su árbol genealógico o su lengua materna. A este trasfondo o ambiente pertenece la diferencia sexual, la cual asegura que se trata de un ambiente sano donde puede florecer la dignidad personal.

\section{Ante Butler: la diferencia sexual, defensa contra las ideologías}

Este punto de vista de un cuerpo originado desde la diferencia hace ver la oposición con Butler, en cuanto que ella considera la diferencia sexual como un elemento opresivo producido por el discurso cultural. Un precursor de la tesis butleriana es el filósofo marxista Louis Althusser, en su escrito sobre la ideología. Pues Althusser amplía las consideraciones de Marx sobre la estructura ideológica capitalista que oprime al proletariado de modo oculto, y la aplica a la misma estructura familiar, que sería la ideología raíz ${ }^{25}$. Según Althusser es ya ideología (es decir, aparato de pensamiento que oculta un objetivo inconfesable) el hecho de que al venir alguien al mundo se le diga «es un niño», o «es

${ }^{25}$ Cfr. Althusser, L., «Idéologie et appareils idéologiques d'État (Notes pour une recherche)», La Pensée 151 (1970) 67-125. 
una niña». De este modo se le encuadra ya en coordenadas de comprensión que le privan subrepticiamente de su libertad.

Pues bien, según se ha mostrado, las cosas se encuentran justamente al revés. Quien quiera eliminar el sustrato de referencia básico constituido por la diferencia hombre-mujer, con la excusa de una mayor libertad, termina haciendo al sujeto esclavo de la voluntad de otros, aquellos que le han traído al mundo. Al pretender rechazar el dato originario de la diferencia, que nos hace a todos igualmente dependientes, se cae en una estructura de sujeción mutua, donde dependemos abusivamente unos de otros.

Por eso es adecuado caracterizar a las teorías que quieren eliminar el trasfondo de la diferencia sexual como ideologías radicales, en cuanto eliminan aquello que nos defiende de toda ideología. La negación de la diferencia sexual acaba produciendo formas de dominio que niegan en su raíz la igualdad básica, y tal negación es, por eso, la verdadera ideología radical. Es justo, por tanto, hablar de «ideología de género». Es la ideología que considera ideológica la diferencia sexual, y de este modo derriba la defensa más radical contra las ideologías. Pues tal defensa se basa sobre la unicidad y dignidad de cada persona, dignidad protegida por la diferencia sexual en la cual esa persona es generada.

\section{Ante Nussbaum: la diferencia sexual, clave para la dignidad de la persona}

Desde el recuerdo de un origen que nos rebasa, origen que está como tatuado en el propio cuerpo, se puede responder también a la posición liberal planteada por Nussbaum. Pues solo aceptando que el origen del hijo se abre más allá de él, y no termina en el querer directo de quien o quienes le han traído al mundo, puede el hijo capacitarse para desear plenamente por sí mismo. Es decir, la lista de capacidades humanas básicas que fundan una ética universal, ha de incluir una receptividad primera atestiguada por nuestro cuerpo y por nuestra condición filial. Solo desde este receptividad originaria, garantizada por la diferencia sexual, podrán desarrollarse en nosotros las capacidades para obrar. La diferencia hombre-mujer resulta, por tanto, extenderse a todas las culturas, en un nivel aún más profundo que las capacidades básicas, pues tal diferencia constituye el sustrato originario que, permitiéndonos acoger nuestro puesto en el mundo, funda toda capacidad de actuar en él.

En la visión liberal, además, se considera que la ampliación de derechos matrimoniales no constituye privación de los derechos de nadie, sino solo un incremento de derechos a otras personas, lo que solo puede ser valorado como 
positivo, se dice, a no ser por los envidiosos. Pero esta conclusión asume ya de entrada que la diferencia sexual no constituye un fundamento para proteger la dignidad de la persona en su mismo nacimiento u origen. Un ejemplo ilustra este punto. Alguien podría introducir, en el campo magnético de la tierra, otros polos móviles de magnitud similar al polo norte o sur, y argüir que solo está introduciendo nuevas posibilidades, sin modificar las que ya había. Pero sabemos que no es así, pues los nuevos polos transformarían el entero campo de fuerza y tendrían como efecto, entre otras cosas, que se hiciera imposible navegar con brújula, al perderse la referencia fija de Norte y Sur. Pues bien, la introducción de nuevas polaridades sexuales, al hacer de la diferencia hombremujer una más entre muchas, la priva de su carácter originario, y la hace incapaz de iluminar ese dato primordial que todo hijo lleva inscrito en su cuerpo y que es irreducible a un propio proyecto autónomo.

Este argumento se mueve cerca del que ha seguido Robert Spaemann para mostrar cómo el derecho contemporáneo sigue necesitando de un concepto de naturaleza ${ }^{26}$. Y esto, no para elaborar una lista de mínimos aceptable por todos, lo cual resulta impensable en la sociedad pluralista de la modernidad. El concepto de naturaleza sigue siendo necesario, argumenta Spaemann, más como un modo de pensar, como la aceptación de algo recibido por todos los hombres, que está en la base de cualquier conversación social sobre la vida común. Y esto se refiere en primer lugar a la pregunta por aquellos que son admitidos a formar parte, como personas, del diálogo social que busca consensos. Pues el criterio que decide esta pregunta no puede ser decidido por consenso de los que ya forman parte, so pena de degenerar en una tiranía. El criterio para responder a esta pregunta solo puede obtenerse acudiendo a una conclusión de la biología: ha de ser contado como persona cualquier individuo que pertenezca a la raza humana.

Pues bien, este argumento de Spaemann puede ser prolongado para incluir la necesidad de la diferencia hombre-mujer. Es decir, la aceptación de esta diferencia depende también de la aceptación de algo natural, entendido como receptividad primera común a todos los hombres. Pues la aceptación de la diferencia sexual va de la mano con la aceptación de que el origen de cada persona es, por un lado, común al de los demás hombres y, por otro, no está determinado totalmente por los otros de forma abusiva.

${ }^{26}$ Cfr. SpaEmann, R., «Die Aktualität des Naturrechts», en ID., Philosophische Essays. Erweiterte Ausgabe, Stuttgart: Reclam, 2012, 60-79. 


\section{La diferencia sexual, más allá de la relación generativa}

El argumento que he empleado se ha basado en la relación filial como clave para la identidad y la dignidad de la persona. Pero se podría ampliar para tener en cuenta cómo la misma diferencia sexual fragua otras relaciones que son también esenciales para la vida personal y común. Las enumero en modo sintético, consciente de que sería necesario un desarrollo más amplio $^{27}$ :

a) La fraternidad. Entre las propuestas de Butler contra la hegemonía heterosexual está el intento de redefinir el concepto de parentela. Para ello hay que interpretar la relación entre los hombres sin referencia a la diferencia se$x^{x u a l}{ }^{28}$. Pero de tal modo se debilita esta misma comunión entre los hombres, que ya no quedan unidos por relaciones de origen común. Es decir, ya no quedan unidos por formar parte de la misma historia, lo cual es una condición esencial para captar el bien del otro como parte integrante del propio bien. El reconocimiento del origen común y de la historia compartida es clave, de hecho, para la experiencia de fraternidad, la cual se desvirtúa si le falta un origen común en la diferencia hombre-mujer.

b) La relación matrimonial. El tipo de unión basado sobre la diferencia sexual es distinto de toda otra unión sexual, pues se realiza en ese lugar preciso donde las personas reconocen su origen de ellas, en cuanto fueron engendradas a su vez a través de la diferencia hombre-mujer. Esto permite que la unión hombre-mujer en el matrimonio se apoye sobre una receptividad originaria que supera a los dos, y les acomuna. Lo cual permite a su vez entender esta unión hombre-mujer como don de sí que nace o brota desde un don que ambos han recibido, liberándoles de toda lógica cerrada de dominación mutua.

c) La paternidad. Solo aceptando la diferencia sexual, trasfondo dado que les supera, pueden padre y madre mirar al hijo como alguien que, por una par-

\footnotetext{
${ }^{27}$ Para un visión más detallada de la antropología relacional que presupongo en esta síntesis, me permito referir al lector a: GRANADOS, J., Teología de la carne. El cuerpo en la historia de su salvación, Madrid: Didaskalos, 2012.

${ }^{28}$ Cfr. Butler, R., «Is Kinship always already heterosexual?», en ID., Undoing Gender, op. cit., 102-130.
} 
te, prosigue la historia de ellos hacia el futuro y, por otra, es libre con respecto a la historia de ellos, y capaz, por tanto, de regenerarla. Solo en este caso, además, pueden asumir los padres la responsabilidad sobre la educación del hijo, sabiendo que no pende directamente sobre los hombros de ellos. Y es que la diferencia sexual ha colocado su unión generativa sobre el terreno de un origen que les precede, y que fundamenta la dignidad única y la libertad del hijo, más allá del deseo de los padres. Del respeto de la diferencia depende, por tanto, la capacidad de la sociedad para inaugurar un futuro que no sea mera repetición del presente.

En suma, he argumentado que la dignidad filial de la persona justifica la necesidad de un trasfondo formado por la diferencia hombre-mujer, el cual no es trasfondo que nos sujete a relaciones opresivas de poder (como pretende Butler) sino, al contrario, trasfondo que posibilita relaciones no basadas solo sobre el poder mutuo. Este trasfondo es la referencia natural básica (natural en cuanto apertura a una receptividad originaria), que permite fundamentar todas las capacidades en las que sostiene Nussbaum su mirada no relativista sobre la ética.

\section{Epílogo: Del leNGUAJE DEL CUERPo A LA FE EN EL CREAdor}

Todo lo dicho plantea una pregunta ulterior, que se refiere al sentido último de la alteridad presente en nuestro cuerpo. Decíamos que para iluminar cabalmente esta alteridad es necesario reconocer que ella no procede en último término del azar o de la necesidad ciega. Y que tal cosa se logra parcialmente al asociar esta alteridad al vínculo con nuestros padres. Pues, en efecto, este vínculo permite acoger la propia corporalidad como buena, en cuanto que se percibe como bueno tal vínculo con ellos.

Ahora bien, tal vínculo no explica del todo la alteridad del cuerpo, pues esta queda abierta más allá de nuestros padres, que no conocen su secreto último, secreto que custodia precisamente la diferencia sexual entre ellos, la cual supera a ambos. En cuanto que la diferencia supone la existencia de un ambiente común entre hombre y mujer, donde se sitúa la relación interpersonal entre ellos y de ellos con sus hijos, se suscita la pregunta por el origen y el fundamento de ese ambiente. Si ese origen último de sentido no existiese, sería imposible reconciliarse con el propio cuerpo, y el cuerpo no sería tampoco espacio de encuentro interpersonal. Se prolonga desde aquí la búsqueda del ori- 
gen, suscitándose la pregunta por el Creador, es decir, por el Dios que es origen último de la vida y de la historia ${ }^{29}$.

Esto significa que la pregunta por la diferencia sexual equivale a la pregunta por el lugar por donde la vida humana se abre a una transcendencia. A Dios no se le encuentra solo en la interioridad aislada (a modo gnóstico), ni es tampoco solo quien ordena el mundo exterior con leyes precisas (según el credo deísta), sino que aparece precisamente en ese terreno corporal que hace posible la relación y unidad entre las personas. Esta es precisamente la imagen bíblica del Dios Creador, que ha inaugurado un ambiente donde puede florecer la vida, y sostiene sin pausa dicho ambiente, presentándose así como la relación que da fundamento a todas nuestras relaciones.

En la perspectiva que hemos delineado, la fe en el Creador surge unida a las experiencias familiares básicas. El camino hacia Él se despliega cuando se constata que el origen del hijo, que atraviesa la diferencia hombre-mujer, se abre más allá de los padres, pues esta diferencia les desborda. El sentido de la vida del hijo queda así liberado del horizonte del deseo de los padres, y apunta hacia un dador de sentido último. Dios aparece, entonces, ligado a la experiencia del amor que nos ha acogido en la vida, como cimiento último que hace posible este amor. Tal vía hacia el Creador puede llamarse «vía de la carne», pues es una vía que parte precisamente de las experiencias originarias del cuerpo, generado desde la diferencia sexual ${ }^{30}$. Se entienden desde aquí estas palabras de Benedicto XVI del 22 diciembre de 2008, donde asoció el problema creado por la ideología del género con la negación de la fe en el Creador:

Si la Iglesia habla de la naturaleza del ser humano como hombre y mujer y pide que se respete este orden de la creación, no se trata de una metafísica superada. Aquí se trata de hecho de la fe en el Creador y de la escucha del lenguaje de la creación, cuyo desprecio llevaría a una auto-

${ }^{29}$ Sobre la cuestión religiosa en Judith Butler, cfr. Armour, E. T. y ST. Ville, S. M. (eds.), Bodily Citations: Religion and Fudith Butler, Bloomington, IN: Indiana University Press, 2006. El libro contiene la respuesta de la misma Butler, que presenta lo transcendente como la fuerza performativa que cuestiona órdenes opresivos (es decir, ante todo el orden de la diferencia hombremujer) e invita, entre otras cosas, a buscar lecturas del Génesis que muestren la posibilidad de este enfoque. Se relativizarían así lecturas exclusivistas promovidas desde el poder, como aquella propuesta, según Butler, por Benedicto XVI, aunque Butler no entra a discutir su pensamiento: cfr. BuTLER, J., «Afterword», en Bodily Citations, op. cit., 276-291.

${ }^{30}$ He tratado de explorar esta vía en GRAnados, J., De carne a gloria. Teología de la creación, Madrid: Didaskalos, 2020. 
destrucción del hombre y por tanto a una destrucción de la misma obra de Dios. Lo que normalmente se expresa y se comprende con el término «gender» se resuelve en definitiva en la autoemancipación del hombre de lo creado y del Creador. El hombre quiere hacerse por sí solo y disponer siempre y exclusivamente por sí solo de todo lo que le atañe. Pero de este modo vive contra la verdad, vive contra el Espíritu Creador ${ }^{31}$.

Esta fe en el Creador resulta entonces decisiva para comprender el sentido último de la diferencia hombre-mujer, de modo que en ella se desvele la clave relacional, tanto de la libertad del hombre, como de su ser. Pues si el ser del mundo procede de un acto de libertad amorosa, el orden del ser, que incluye la diferencia sexual, no será un orden opresivo que impida la libertad, sino un orden generativo donde la libertad puede arraigarse y florecer.

31 BenEDICTO XVI, «Discurso a la curia romana» (22 de diciembre de 2008), AAS 101 (2009) 4856,53 . 
JOSÉ GRANADOS

\section{Bibliografía}

AbBey, R., The Return of Feminist Liberalism, Montreal: McGill-Queen's University Press, 2011.

Althusser, L., «Idéologie et appareils idéologiques d'État (Notes pour une recherche)», La Pensée 151 (1970) 67-125.

Armour, E. T. y ST. Ville, S. M. (eds.), Bodily Citations: Religion and fudith Butler, Bloomington, IN: Indiana University Press, 2006.

BENEDICTO XVI, «Discurso a la curia romana» (21 de diciembre de 2012), AAS 105 (2013) 47-54.

BENEDICTO XVI, «Discurso a la curia romana» (22 de diciembre de 2008), AAS 101 (2009) 48-56.

BROwn, P., The body and society: men, women and sexual renunciation in early Christianity, New York: Columbia University Press, 1988.

ButLer, J., Gender trouble: Feminism and the subversion of identity, New YorkLondon: Routledge, 2011 [1990].

Butler, J., Bodies That Matter: On the Discursive Limits of Sex, New YorkLondon: Routledge, 1993.

Butler, J., Undoing gender, New York-London: Psychology Press, 2004.

Butler, J., «Afterword», en Armour, E. T. y ST. Ville, S. M. (eds.), Bodily Citations: Religion and Judith Butler, Bloomington, IN: Indiana University Press, 2006, 276-291.

Gauchet, M., «L'enfant du désir», Le Débat 132 (2004) 98-121.

Granados, J., Teología de la carne. El cuerpo en la historia de su salvación, Madrid: Didaskalos, 2012.

Granados, J., De carne a gloria. Teología de la creación, Madrid: Didaskalos, 2020.

Habermas, J., Die Zukunft der menschlichen Natur: Auf dem Weg zu einer liberalen Eugenik?, Frankfurt: Suhrkamp, 2001.

Hopper, E., The Social Unconscious, Philadelphia: J. Kingsley, 2003.

Kampowski, S. y Moltisanti, D. (eds.), Migliorare l'uomo? La sfida etica dell'enhancement, Siena: Cantagalli, 2011.

MACKENZIE, J., «Refiguring Universalism: Martha Nussbaum and Judith Butler - An Uneasy Alliance?», Australian Feminist Studies 24 (2009) 343-358.

MARCEL, G., «L'être incarné, repère central de la réflexion métaphysique», en ID., Du refus à l'invocation, Paris: Gallimard, 1940, 19-54. 
Merleau-Ponty, M., Phénoménologie de la perception, Paris: Gallimard, 1945, 175.

Nussbaum, M. C., «Nature, Function, and Capability: Aristotle on Political Distribution», Oxford Studies in Ancient Philosophy, Supplementary Volume 1 (1988) 145-184.

Nussbaum, M. C., «Human Functioning and Social Justice: In Defense of Aristotelian Essentialism», Political Theory 20 (1992) 202-246.

Nussbaum, M. C., «Aristotle on Human Nature and the Foundations of Ethics», en Altham, J. E. J. y HarRison, R. (eds.), World, Mind, and Ethics: Essays on the Ethical Philosophy of Bernard Williams, Cambridge: Cambridge University Press, 1995, 86-131.

Nussbaum, M. C., «Constructing Love, Desire, and Care», en Nussbaum, M. C. y Estlund, D. M. (eds.), Sex, Preference, and Family: Essays on Law and Nature, Oxford: Oxford University Press, 1997, 253-276.

Nussbaum, M. C., Sex \& social justice, Oxford: Oxford University Press, 1999.

Nussbaum, M. C., «Platonic Love and Colorado Law», en ID., Sex \& social justice, Oxford: Oxford University Press, 1999, 299-331.

Nussbaum, M. C., «A Defense of Lesbian and Gay Rights», en ID., Sex \& social justice, Oxford: Oxford University Press, 1999, 184-210.

Nussbaum, M. C., «The Professor of Parody: the Hip Defeatism of Judith Butler», New Republic 220 (1999) 37-45.

Nussbaum, M. C., «Non-Relative Virtues: An Aristotelian Approach», Midwest Studies In Philosophy 13 (1988) 32-53.

Ricoeur, P., Soi-même comme un autre, Paris: Seuil, 1990.

Ricoeur, P., De l'interpretation. Essai sur Freud, Paris: Seuil, 2014 [1965].

SpaEManN, R., «Die Aktualität des Naturrechts», en ID., Philosophische Essays. Erweiterte Ausgabe, Stuttgart: Reclam, 2012, 60-79.

WeInBerg, H., «So What is this Social Unconscious Anyway?», Group Analysis 40 (2007) 307-322. 
